\title{
Dietary restriction of energy and sugar results in a reduction in human cytochrome P450 2E1 activity
}

\author{
Isabelle Leclercq, Yves Horsmans*, Jean-Pierre Desager, Stanislas Pauwels and André P. Geubel \\ Gastroenterology Unit, Université Catholique de Louvain, Brussels, Belgium
}

(Received 28 July 1998 - Revised 23 March 1999 - Accepted 7 May 1999)

\begin{abstract}
Dietary habits are often considered as a pathogenic factor for fatty liver. The impact of dietary intake and steatosis on drug metabolism remains poorly investigated. Our aim was to assess the effect of dietary intake on in vivo cytochrome P450 (CYP) activities in eleven patients with abnormal liver function tests potentially due to fatty liver and associated with a high-sugar diet. Liver function tests, liver volume, aminopyrine breath test (ABT) and chlorzoxazone (CZ) pharmacokinetics (area under the curve, AUC) which are known to reflect CYP2E1 activity were evaluated before and after 2 months restriction of dietary sugar intake. Features at inclusion were an increased BMI (30.3 (SD 3.2) kg/m²), high hepatic volume (1.96 (SD 0.48) litres), hyperechogenic liver parenchyma, elevated liver enzyme activities (alanine aminotransferase $(E C$ 2.6.1.2) 58.6 (SD 17.4) IU/l with alanine aminotransferase : aspartate aminotransferase ( $E C$ 2.6.1.1) ratio $>1$ ), together with a normal ABT value (0.68 (SD 0.21) \% specific activity of administered dose of $\left[{ }^{14} \mathrm{C}\right]$ aminopyrine in breath after $1 \mathrm{~h}$ ) and a high CYP2E1 activity (CZ AUC 20.3 (SD 7.1) $\mu \mathrm{g} / \mathrm{ml}$ per h). A dietary sugar restriction was prescribed. On the basis of repeated interviews by the same dietitian, unaware of any clinical and biochemical data, six patients remained compliant to the diet and exhibited reductions in BMI $(P<0.001)$, serum alanine aminotransferase $(P=0.008)$, liver volume $(P=0.002)$ and CYP2E1 activity $(P=0.007)$, a significant increase in ABT $(P<0.001)$ together with the disappearance of liver hyperechogenicity at ultrasound. In contrast, the five non-compliant patients did not show any significant change in any of these variables. In conclusion, CYP2E1 activity is induced in patients with perturbations of liver function tests potentially due to fatty liver. In these patients, effective dietary sugar restriction is associated with a reduction in liver volume, a reduction in CYP2E1 activity and an increased aminopyrine metabolism rate.
\end{abstract}

Cytochrome P450: Aminopyrine: Chlorzoxazone: Liver

Liver fatty infiltration, i.e. steatosis, is a common condition often associated with malnutrition, starvation, jejunoileal bypass, gastric partitioning, diabetes mellitus, obesity, total parenteral nutrition (Burt et al. 1991; Alpers et al. 1993; Day \& Yeaman, 1994), and carbohydrate-enriched diet (Acheson et al. 1984; Frayn \& Kingman, 1995). Enhancement of the expression and activity of the hepatic lipogenic enzymes by a high-carbohydrate diet is a well known phenomenon able to produce liver steatosis (Acheson et al. 1984; Frayn \& Kingman, 1995; Aarsland et al. 1997).

The impact of dietary intake and steatosis on liver metabolic functions remains unclear. In healthy subjects, energy intake restriction decreases aminopyrine clearance (Krishnaswamy et al. 1984). In patients with steatohepatitis, a single study aimed at investigating cytochrome P450 (CYP) activity showed that antipyrine clearance is dramatically impaired in this condition and is improved following dietary therapy (Fiatarone et al. 1991). Evidence has also been provided that transplanting a steatotic liver significantly increases the risk of primary non-function (Adam et al. 1991; Ploeg et al. 1993). Liver steatosis is also a probable risk factor for halothane or acetaminophen hepatotoxicity (Black, 1984; Cousins et al. 1989), an event known to be influenced by the level of CYP2E1 activity (Raucy et al. 1989; Kharasch et al. 1996).

To assess the effect of dietary intake and steatosis on CYP, we investigated a group of such patients for aminopyrine demethylation and chlorzoxazone $(\mathrm{CZ})$ pharmacokinetics at the time of inclusion in the study and after 2 months dietary sugar restriction.

\footnotetext{
Abbreviations: ABT, aminopyrine breath test; ALT, alanine aminotransferase; AST, aspartate aminotransferase; AUC, area under the curve; CYP, cytochrome P450; CZ, chlorzoxazone; SA, specific activity.

* Corresponding author: Dr Y. Horsmans, fax +32 2764 8272, email Horsmans@gaen.ucl.ac.be
} 


\section{Subjects and methods}

\section{Subjects}

Caucasian patients ( $n$ 11: nine males and two females) aged from 25 to 64 years (mean age 44.9 (SD 11.6) years) participated in the investigation. The protocol was approved by the St-Luc University Hospital ethical committee (Catholic University of Louvain, Brussels, Belgium) and all patients gave written informed consent before taking part in the study. Criteria for diagnosis were a compatible clinical history, a hyperechogenic liver parenchyma at upper abdominal ultrasound (Osawa \& Mori, 1996) together with abnormal liver function tests characterized by an alanine aminotransferase (EC 2.6.1.2): aspartate aminotransferase (EC 2.6.1.1) (ALT:AST) ratio $>1$ in the absence of any other detectable cause of liver injury. Before inclusion, a complete clinical history including height and weight, previous history of transfusion and associated non-hepatic conditions was obtained in all cases together with a routine clinical examination and biochemical data. Wilson's disease, viral hepatitis B and C, auto-immune hepatitis, $\alpha_{1}$-antitrypsin deficiency and haemochromatosis were excluded on the basis of biochemical work-up. A detailed alcohol intake appraisal was obtained by two different physicians, ten patients being abstinent while the remaining patient drank less than $20 \mathrm{~g}$ alcohol per week. Moreover, in all patients the AST:ALT ratio, uric acid concentration and erythrocyte mean corpuscular volume did not show any change suggestive of excessive alcohol consumption. No patient was taking any medication known to produce liver injury or to influence CYP activities (Table 1). A single subject (patient 8) was smoking five to ten cigarettes per day.

At both the time of diagnosis and at inclusion in the study, a dietary inquiry was performed by the same dietitian. A detailed questionnaire about diet ingested during the preceding week was provided by each patient including a precise quantification of food and beverages ingested during the $3 \mathrm{~d}$ before inclusion in the study.

After an overnight fast, blood count, standard liver function tests (serum albumin, bilirubin, ALT and AST, alkaline phosphatase (EC 3.1.3.1), $\gamma$-glutamyl transferase (EC 2.3.2.2)), prothrombin time, ferritin, glucose, $\beta$-hydroxybutyrate, insulin and glycated haemoglobin, triacylglycerol and cholesterol concentrations were determined by routine clinical methods. Patients 2 and 9 underwent a $75 \mathrm{~g} 2 \mathrm{~h}$ glucose-tolerance test because of slightly elevated fasting blood glucose. Liver volume, aminopyrine demethylation rate and $\mathrm{CZ}$ pharmacokinetics were performed on the same day.

A dietary reduction in mono- and disaccharide intake without change in protein and lipid intake was prescribed for a 2-month period. Compliance to the diet was evaluated by weekly interviews performed by telephone and repeated interviews performed in person by the same dietitian, who was unaware of any clinical and biochemical data, after 1 month and at the end of the study. In addition, each patient made a precise determination of the quantity of food and beverages ingested during the $3 \mathrm{~d}$ preceding the inclusion in the study.

At 2 months, physical examination, recent clinical history,

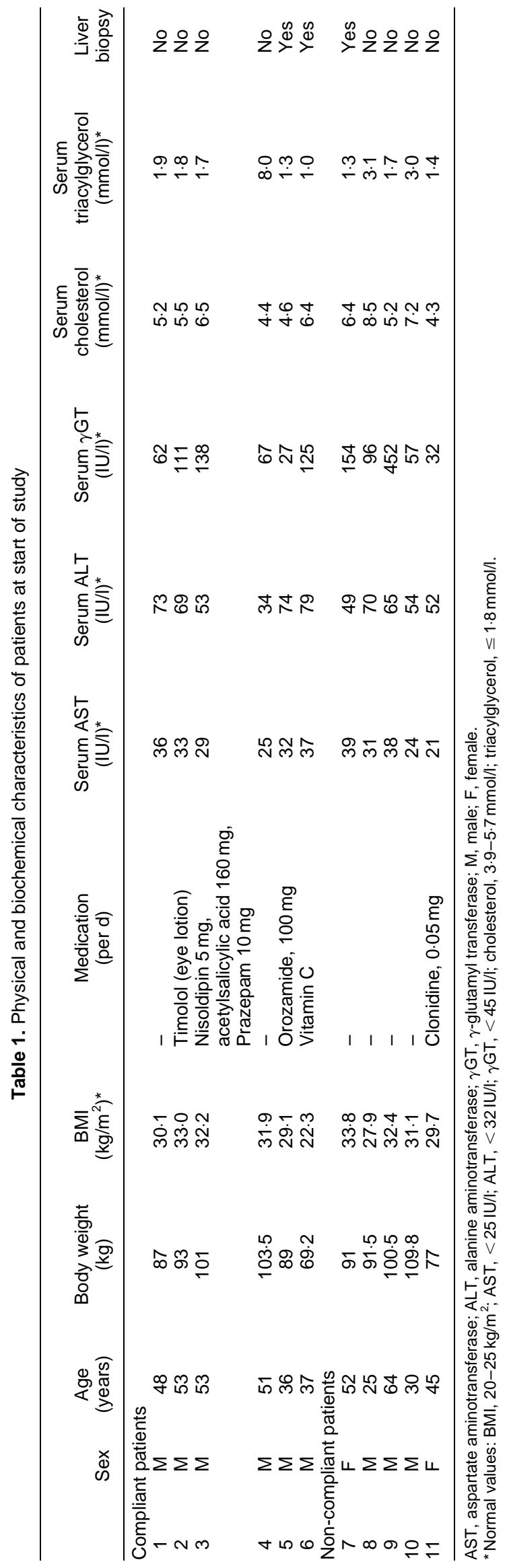


blood tests, liver ultrasound, liver volume, aminopyrine demethylation rate and $\mathrm{CZ}$ pharmacokinetics were repeated.

Liver biopsies performed in three patients within 1 month (patient 7), 2 years (patient 6) and 8 years (patient 5) before inclusion showed characteristic features of steatohepatitis (Lee, 1989).

\section{Methods}

Liver volume was evaluated by single proton emission tomography of the liver after intravenous injection of approximately $110 \mathrm{MBq}{ }^{99 \mathrm{~m}} \mathrm{Tc}$-labelled sulfur colloid. Single proton emission tomography acquisitions were performed on a single head camera (400AC/T, GE, Milwaukee, WI, USA) equipped with a LEHR collimator in a $64 \times 64$ matrix (pixel size $6.5 \mathrm{~mm}$ ) using a $20 \%$ window around the photopeak; sixty-four projections were acquired along an elliptical orbit. The data were reconstructed using the filtered back projection algorithm with a Shepp-Logan filter and a Hanning window. The V filter (Kuwahara \& Hachimura, 1980) was then applied on the transverse slices: this filter smoothes the activity inside the liver without significant reduction of the contrast of the liver contour. The number of voxels included in the liver were further determined using the Gy histogram method (Mortelmans et al. 1986).

CYP1A2 and -3A activities were evaluated using the $\left[{ }^{14} \mathrm{C}\right]$ aminopyrine breath test (ABT) as previously described by our group (Horsmans et al. 1995b). Briefly, fasting patients were given an intravenous trace dose of the labelled compound $\left(37 \cdot 0-55 \cdot 5 \mathrm{~Bq}\left[{ }^{14} \mathrm{C}\right]\right.$ aminopyrine). Breath $\left[{ }^{14} \mathrm{C}\right]$ activity was measured $1 \mathrm{~h}$ after injection, and the specific activity (SA), corrected for body weight, was expressed as the percentage of the administered dose (SA $1 \mathrm{~h} \%$ ). In healthy volunteers whose mean age was 27 years $\mathrm{ABT}$ values were 0.60 (SD 0.15) SA $1 \mathrm{~h} \%$ (Horsmans et al. 1995a).

CYP2E1 activity was assessed by the pharmacokinetics of $\mathrm{CZ}$ and its metabolite 6-hydroxychlorzoxazone (Girre et al. 1994) following oral administration of CZ (500 mg) (Sigma Chemicals Co., St Louis, MO, USA) and agreed for human use by the pharmaceutical department of the University St-Luc Hospital, Brussels, Belgium). Venous blood samples were drawn before drug intake and 0.5, 1, 1.5, 2, 3, 4, 5, 6, 7 and $8 \mathrm{~h}$ thereafter. Plasma CZ and 6-hydroxychlorzoxazone were determined by a reverse-phase HPLCbased assay as recently described by our group (Leclercq et al. 1998b).

The individual CZ and 6-hydroxychlorzoxazone pharmacokinetic data were processed by the ELSFIT program (Sheiner, 1983). Data were expressed as the $\mathrm{CZ}$ area under the curve (CZ AUC) in $\mu \mathrm{g} / \mathrm{ml}$ per $\mathrm{h}$. In healthy subjects whose mean age was 38 years, CZ AUC was 46.7 (SD 14.6) $\mu \mathrm{g} / \mathrm{ml}$ per h (Leclercq et al. 1998a).

\section{Statistical analysis}

Data are expressed as means and standard deviations. Comparisons between variables before and after normoglucidic diet were performed using the paired Student's $t$ test, with $P \leq 0.05$ taken as the lower limit of statistical significance. The correlation between the extent of weight reduction and CYP2E1 activity reduction was examined by calculating Spearman's rank correlation coefficient, $r_{\mathrm{s}}$.

\section{Results}

At the time of diagnosis all patients were taking a highsugar diet in which 47 (SD 8) \% of total daily energy intake (11.34 (SD 2.94) MJ/d) was supplied as carbohydrate (of which 2.94 (SD 1.43) MJ/d was mono- and disaccharides), 1.68 (SD 0.36) MJ/d was from protein, and 4.33 (SD 0.70) $\mathrm{MJ} / \mathrm{d}$ was from lipid. Ten out of eleven patients had a slightly excessive body weight while patient 6 had a normal weight. Typical biochemical abnormalities included a 2fold increase in serum ALT with ALT : AST ratio $>1$ and a $2 \cdot 5$-fold increase in serum $\gamma$-glutamyl transferase. Serum bilirubin, albumin concentration and prothrombin time were normal in all instances. Fasting serum cholesterol and triacylglycerol concentrations at diagnosis are listed in Table 1. Serum $\beta$-hydroxybutyrate and fasting insulin concentrations were normal in all instances. The glucosetolerance test performed in patients 2 and 9 because of slightly elevated fasting plasma glucose showed a moderate postprandial hypoglycaemia. Serum Fe concentration was normal in all cases while serum ferritin was slightly increased in five patients (patients $1,4,5,8$ and 9) with values ranging from 300 to $340 \mathrm{ng} / \mathrm{ml}$ (normal value $<300 \mathrm{ng} / \mathrm{ml}$ ).

At diagnosis, the mean hepatic volume was 1.96 (SD 0.48) litres. ABT values showed a wide inter-individual variability (0.68 (SD 0.21) SA $1 \mathrm{~h} \%$; range $0 \cdot 37-1 \cdot 14 \%$ ) (Fig. 1(a)). CZ AUC value in the whole group was $20 \cdot 3$ (SD 7.1) $\mu \mathrm{g} / \mathrm{ml}$ per $\mathrm{h}$; the individual values ranged from 9.8 to $31.0 \mu \mathrm{g} / \mathrm{ml}$ per h (Fig. 1(b)).

\section{Effect of diet on laboratory findings, liver volume, cytochrome P450 activity and liver echogenicity}

On the basis of repeated interviews by the dietitian, who was unaware of any clinical and biochemical data, six patients were found to be compliant to the $50 \%$ reduction in monoand disaccharide dietary supply (1.08 (SD 0.49) MJ/d v. 3.56 (SD 1.26) $\mathrm{MJ} / \mathrm{d}$ at inclusion; $P=0.01$ ). The five remaining patients did not modify their dietary habits, the total energy supply remaining unchanged (10.45 (SD 2.89) MJ/d after 2 months $v .10 \cdot 19$ (SD 2.78) MJ/d at inclusion from which 3.02 (SD 0.63) MJ/d v. 2.81 (SD 1.26) was provided as mono- and disaccharides) (Table 2).

In the group overall, serum ALT, liver volume, ABT and CZ AUC values did not show any significant change (Table 3).

In the six compliant patients, the change in diet led to a significant reduction in body weight $(85.3$ (SD 11.5$) \mathrm{kg} v$. 90.5 (SD 12.3) kg; $P<0.001)$, BMI $(P<0.001)$, serum ALT $(P=0.008)$, hepatic volume $(P=0.002)$ and to disappearance of liver hyperechogenicity at ultrasound. ABT values, however, were significantly increased $(P<0 \cdot 001)$ (Table 3 and Fig. 1(a)). In this group, the 2-months sugar-restricted diet also resulted in a significant decrease in CYP2E1 activity as demonstrated by a significant increase in $\mathrm{CZ}$ AUC $(P=0.007)$ (Table 3 and Fig. 1(b)). A significant correlation was observed between the extent of weight reduction and variation in CZ AUC level $\left(r_{\mathrm{s}} 0 \cdot 57, P=0 \cdot 008\right)$.

In the five non-compliant subjects, BMI remained unchanged, serum ALT increased $(P=0 \cdot 03)$ whereas ABT values, hepatic volume, hyperechogenic aspect of the liver 
(a)

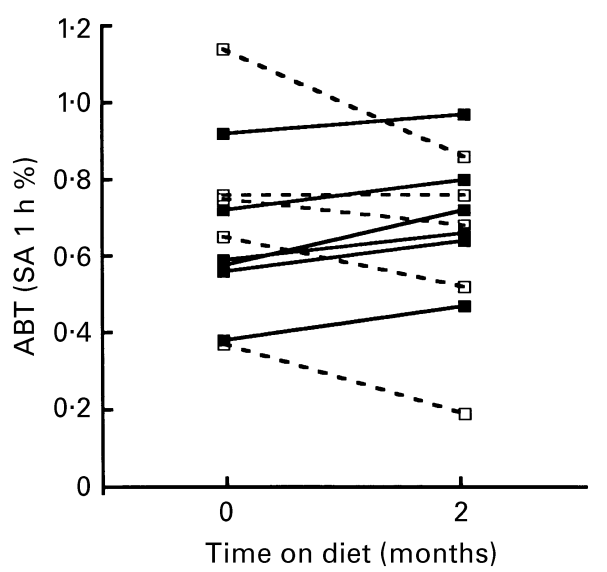

(b)

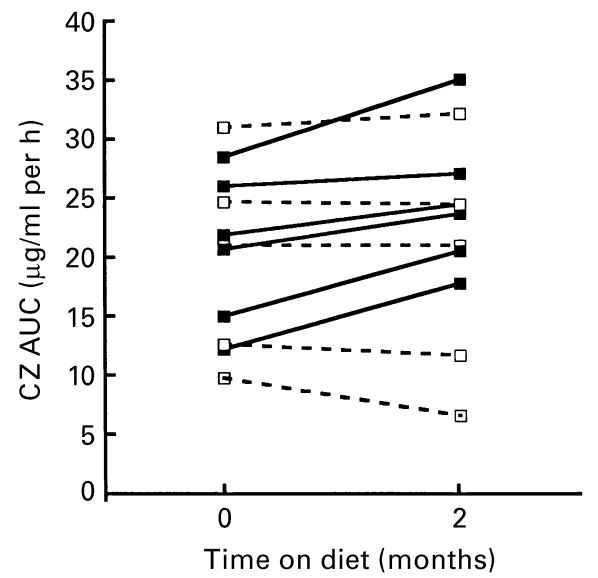

Fig. 1. Effect of dietary sugar restriction on compliant $(n 6)(\square-\square)$ and non-compliant $(n 5)(\square---\square)$ patients with elevated serum liver enzymes probably related to fatty liver. (a) Aminopyrine breath test (ABT) to asess cytochrome P450 $1 \mathrm{~A} 2$ and $3 \mathrm{~A}$ activities and (b) chlorzoxazone area under the curve (CZ AUC) after oral ingestion of $500 \mathrm{mg}$ chlorzoxazone to assess cytochrome P450 2E1 activities at the start of the study and 2 months later. SA $1 \mathrm{~h} \%$, percentage of specific activity of administered dose of $\left[{ }^{14} \mathrm{C}\right]$ aminopyrine in the breath after $1 \mathrm{~h}$. For details of procedures, see p. 259.

at ultrasound and pharmacokinetic parameters of $\mathrm{CZ}$ did not change significantly (Table 3 and Fig. 1(b)).

\section{Discussion}

A group of patients with elevated serum liver enzymes probably related to fatty liver as assessed by the evidence of a hyperechogenic liver parenchyma, in the absence of any other detectable cause of liver injury and occurring together with a high-sugar diet, was investigated for CYP activities. Changes occurring after a 2-month sugar-restricted diet were also documented.

Liver fat accumulation was directly confirmed in three cases by a liver biopsy performed before the study and indirectly in six patients on the basis of the improvement in biochemical and echographic features following mono- and disaccharide intake restriction (Eriksson et al. 1986; Keeffe et al. 1987). In patients compliant to the prescribed diet a significant decrease in BMI and an improvement of liver function tests occurred. Moreover, in the same group dietary changes were associated with an increase in CYP1A2 and CYP3A activities and a decrease in CYP2E1 activity as assessed by the ABT and the pharmacokinetics of $\mathrm{CZ}$ respectively. In contrast, non-compliant patients did not show any significant change in any of these variables. Our data thus suggest that, in compliant patients, effective sugar restriction results in an increase in ABT values, a reduction in CYP2E1 activity and a decrease in fat liver storage. Even though an age-matched healthy control group was not included, comparison of this group of patients with probable fatty liver with historical control groups of healthy subjects (Horsmans et al. 1995a; Leclercq et al. 1998a) provides further arguments suggesting that CYP2E1 activity is induced in this condition.

Until now, the effect of dietary changes on CYP activities has mainly been investigated in healthy subjects showing that energy intake restriction (protein, lipid and carbohydrate ratio being unchanged) decreases aminopyrine clearance (Krishnaswamy et al. 1984). In contrast, in our patients the opposite effect was observed, as was previously reported in a similar group of patients using antipyrine clearance (Fiatarone et al. 1991) as a marker of CYP1A2 and CYP3A activities. Recently it has also been shown using immunohistochemistry of liver biopsy material that hepatic CYP2E1

Table 2. Composition of diet of patients $(n 11)$ with elevated serum liver enzymes at the start of and after 2 months of prescription of a dietary sugar restriction

(Values are means and standard deviations)

\begin{tabular}{|c|c|c|c|c|c|c|c|c|}
\hline & \multicolumn{4}{|c|}{$\begin{array}{l}\text { Patients compliant to the } \\
\text { sugar restriction }(n 6)\end{array}$} & \multicolumn{4}{|c|}{$\begin{array}{l}\text { Patients uncompliant to the } \\
\text { sugar restriction }(n 5)\end{array}$} \\
\hline & \multicolumn{2}{|c|}{ At inclusion } & \multicolumn{2}{|c|}{ At 2 months } & \multicolumn{2}{|c|}{ At inclusion } & \multicolumn{2}{|c|}{ At 2 months } \\
\hline & Mean & SD & Mean & SD & Mean & SD & Mean & SD \\
\hline Total energy intake (MJ/d) & 12.56 & $2 \cdot 81$ & $9 \cdot 48^{* *}$ & $2 \cdot 15$ & $10 \cdot 19$ & 2.78 & $10 \cdot 45$ & $2 \cdot 89$ \\
\hline Protein (\% total energy intake) & 13.9 & $5 \cdot 6$ & $16 \cdot 2$ & 1.4 & $15 \cdot 9$ & 4.2 & $15 \cdot 8$ & $4 \cdot 2$ \\
\hline Lipid (\% total energy intake) & $36 \cdot 4$ & 8.0 & 38.6 & 4.6 & $40 \cdot 6$ & $2 \cdot 1$ & 38.9 & $5 \cdot 3$ \\
\hline Glucids (\% total energy intake) & 49.7 & $10 \cdot 8$ & $45 \cdot 1$ & 5.8 & $43 \cdot 3$ & 2.2 & $45 \cdot 3$ & $7 \cdot 2$ \\
\hline Mono- and disaccharides (\% total energy intake) & 28.5 & 8.2 & $11 \cdot 5^{\star * *}$ & 4.4 & $20 \cdot 2$ & 6.8 & $18 \cdot 0$ & $5 \cdot 8$ \\
\hline
\end{tabular}

Mean value was significantly different from that at the start of the study: ${ }^{\star \star} P<0.01,{ }^{\star \star \star} P<0.001$. 
Table 3. BMI, serum alanine aminotransferase (ALT), liver volume, aminopyrine breath test (ABT) and pharmacokinetics of chlorzoxazone (CZ AUC) in patients at inclusion and after 2 months of prescription of dietary sugar restriction $†$

(Values are means and standard deviations)

\begin{tabular}{|c|c|c|c|c|c|c|}
\hline & & \multirow[b]{2}{*}{$n$} & \multicolumn{2}{|c|}{ At start of study } & \multicolumn{2}{|c|}{ After 2 months } \\
\hline & & & Mean & SD & Mean & SD \\
\hline $\mathrm{BMI}\left(\mathrm{kg} / \mathrm{m}^{2}\right)$ & $\begin{array}{l}\text { All } \\
\text { Compliant patients } \\
\text { Non-compliant patients }\end{array}$ & $\begin{array}{r}11 \\
6 \\
5\end{array}$ & $\begin{array}{l}30 \cdot 3 \\
29 \cdot 8 \\
30 \cdot 0\end{array}$ & $\begin{array}{l}3 \cdot 2 \\
3 \cdot 9 \\
2 \cdot 3\end{array}$ & $\begin{array}{l}29 \cdot 0^{\star * \star} \\
28 \cdot 1^{\star \star *} \\
30 \cdot 1\end{array}$ & $\begin{array}{l}3.0 \\
3.6 \\
1.9\end{array}$ \\
\hline Serum ALT (IU/I) & $\begin{array}{l}\text { All } \\
\text { Compliant patients } \\
\text { Non-compliant patients }\end{array}$ & $\begin{array}{r}11 \\
6 \\
5\end{array}$ & $\begin{array}{l}58 \cdot 6 \\
63 \cdot 7 \\
52 \cdot 6\end{array}$ & $\begin{array}{l}17 \cdot 4 \\
17 \cdot 0 \\
17 \cdot 6\end{array}$ & $\begin{array}{l}63 \cdot 1 \\
41 \cdot 7^{* *} \\
88 \cdot 8^{*}\end{array}$ & $\begin{array}{r}27 \cdot 7 \\
8 \cdot 3 \\
17 \cdot 8\end{array}$ \\
\hline Liver volume (litres) & $\begin{array}{l}\text { All } \\
\text { Compliant patients } \\
\text { Non-compliant patients }\end{array}$ & $\begin{array}{r}11 \\
6 \\
5\end{array}$ & $\begin{array}{l}1 \cdot 96 \\
2 \cdot 12 \\
1 \cdot 76\end{array}$ & $\begin{array}{l}0.51 \\
0.43 \\
0.59\end{array}$ & $\begin{array}{l}1.84 \\
1.87^{\star \star} \\
1.80\end{array}$ & $\begin{array}{l}0.44 \\
0.36 \\
0.57\end{array}$ \\
\hline ABT (SA $1 \mathrm{~h} \%)$ & $\begin{array}{l}\text { All } \\
\text { Compliant patients } \\
\text { Non-compliant patients }\end{array}$ & $\begin{array}{r}11 \\
6 \\
5\end{array}$ & $\begin{array}{l}0.68 \\
0.63 \\
0.73\end{array}$ & $\begin{array}{l}0.21 \\
0.21 \\
0.28\end{array}$ & $\begin{array}{l}0.67 \\
0.71^{* * *} \\
0.62\end{array}$ & $\begin{array}{l}0.21 \\
0.17 \\
0.28\end{array}$ \\
\hline CZ AUC $(\mu \mathrm{g} / \mathrm{ml}$ per $\mathrm{h})$ & $\begin{array}{l}\text { All } \\
\text { Compliant patients } \\
\text { Non-compliant patients }\end{array}$ & $\begin{array}{r}11 \\
6 \\
5\end{array}$ & $\begin{array}{l}20 \cdot 3 \\
20 \cdot 7 \\
19 \cdot 8\end{array}$ & $\begin{array}{l}7 \cdot 1 \\
6 \cdot 3 \\
8 \cdot 7\end{array}$ & $\begin{array}{l}22 \cdot 3 \\
24 \cdot 7^{\star *} \\
20 \cdot 6\end{array}$ & $\begin{array}{r}8.4 \\
6 \cdot 0 \\
11 \cdot 2\end{array}$ \\
\hline
\end{tabular}

CZ AUC, chlorzoxazone area under the curve; SA $1 \mathrm{~h} \%$, percentage of specific activity of administered dose of $\left[{ }^{14} \mathrm{C}\right] \mathrm{amino}-$ pyrine in the breath after $1 \mathrm{~h}$.

Mean value was significantly different from that at start of study: ${ }^{*} P<0.05,{ }^{* *} P<0.01,{ }^{* * *} P<0.001$.

†For details of procedures see p. 259.

content is increased in patients with steatohepatitis whereas CYP3A is decreased compared with normal livers (Weltman et al. 1998). Taken together, these data suggest that steatosis per se and not only dietary sugar restriction may play a role in the observed inhibition of CYP1A2 and CYP3A activities. Conversely, the significant correlation observed between the extent of weight reduction and the extent of CYP2E1 activity reduction favours another hypothesis: a direct relationship between the modulation of CYP2E1 activity and the subject's volume of distribution.

To our knowledge, the effect of dietary composition on CYP2E1 has rarely been studied in human subjects. Using CZ pharmacokinetics, we have shown that in healthy subjects CYP2E1 activity is decreased by watercress (Nasturtium officinale) ingestion (Leclercq et al. 1998a). In contrast, CYP2E1 activity has been found to be elevated in obesity (O'Shea et al. 1994), uncontrolled diabetes mellitus (Song et al. 1990), and in clinical situations associated with liver steatosis. In uncontrolled diabetes mellitus, increased serum ketone bodies have been suggested to induce a pretranslational activation of CYP2E1 (Barnett et al. 1988; Yun et al. 1991). In obese subjects (O'Shea et al. 1994) as in our patients, CYP2E1 modulation was, however, observed in the absence of ketosis. Hypoinsulinaemia has also been implicated since an induced CYP2E1 activity in human lymphocytes from poorly controlled insulin-dependent diabetics has been described (Song et al. 1990). In our patients, the role of such a mechanism involving an imbalance between glucose level and insulin secretion is also unlikely to be involved since serum glucose, insulin, glycated haemoglobin and glucose-tolerance test were all in the normal range.

Changes in CYP2E1 activities observed in our patients may also be directly related to the degree of steatosis and/or to inflammation which may be associated with steatosis. Mediators of inflammation are known to down-regulate the expression of many CYP (Abdel-Razzak et al. 1993; Tapner et al. 1996) or, like interleukin 4, to induce CYP2E1 expression and activity (Abdel-Razzak et al. 1993).

In our patients, dietary intervention led to a reduction in energy intake and also a reduction in the dietary content of mono- and disaccharides. Therefore, observed changes may be related to either or both of these effects directly or through the improvement of liver steatosis.

Future studies should thus evaluate the relative impact of steatosis, energy restriction, and sugar restriction on the changes in CYP activities observed in patients with fatty liver. For ethical reasons, a validated method of noninvasive assessment of steatosis should be used for this purpose.

In conclusion, in patients with elevated serum liver enzymes probably related to fatty liver, effective energy and sugar restriction is associated with a reduction in body weight, liver volume, CYP2E1 activity and an increase in ABT values. Dietary habits should be taken into account when assessing liver function and when administering xenobiotics in such a setting.

\section{Acknowledgement}

This study was supported by a research grant from GlaxoWellcome, Belgium.

\section{References}

Aarsland A, Chinkes D \& Wolf RR (1997) Hepatic and wholebody fat synthesis in humans during carbohydrate overfeeding. American Journal of Clinical Nutrition 65, 1774-1782. 
Abdel-Razzak Z, Loyer P, Fautrel A, Gautier JC, Corcos L, Turlin B \& Guillouzo A (1993) Cytokines down-regulate expression of major cytochrome P-450 enzymes in adult human hepatocytes in primary cultures. Molecular Pharmacology 44, 707-715.

Acheson KJ, Schutz Y, Bessard T, Ravussin E, Jequier E \& Flatt JP (1984) Nutritional influences on lipogenesis and thermogenesis after a carbohydrate meal. American Journal of Physiology 246, E62-E70.

Adam R, Reynes M, Johann M, Morino M, Astarcioglu I, Kafetzis I, Castaing D \& Bismuth H (1991) The outcome of steatotic grafts in liver transplantation. Transplantation Proceedings 23, $1538-1540$

Alpers DH, Sabesin SM \& White HM (1993) Fatty liver: biochemical and clinical aspects. In Diseases of the Liver, 7th ed., pp. 825-871 [L Schiff and ER Schiff, editors]. Philadelphia, PA: JB Lippincott Company.

Barnett CR, Flatt PR \& Ioannides C (1988) Role of ketone bodies in the diabetes-induced changes in hepatic mixed-function oxidase activities. Biochimica et Biophysica Acta 967, 250-254.

Black M (1984) Acetaminophen hepatotoxicity. Annual Review of Medicine 35, 577-593.

Burt AD, MacSween RNM, Peters TJ \& Simpson KJ (1991) Nonalcoholic fatty liver: causes and complications. In Oxford Textbook of Clinical Hepatology, pp. 865-871 [N McIntyre, JP Benhamou, J Bircher, M Rizetto and J Rodes, editors]. Oxford: Oxford University Press.

Cousins MJ, Plummer JL \& Hall PM (1989) Risk factors for halothane hepatitis. Australian New Zealand Journal of Surgery 59, 5-14.

Day CP \& Yeaman SJ (1994) The biochemistry of alcohol-induced fatty liver. Biochimica et Biophysica Acta 1215, 33-48.

Eriksson S, Eriksson KF \& Bondesson L (1986) Nonalcoholic steatohepatitis in obesity: a reversible condition. Acta Medica Scandinavica 220, 83-88.

Fiatarone JR, Coverdale SA, Batey RG \& Farrell GC (1991) Nonalcoholic steatohepatitis: impaired antipyrine metabolism and hypertriglyceridaemia may be clues to its pathogenesis. Journal of Gastroenterology and Hepatology 6, 585-590.

Frayn K \& Kingman S (1995) Dietary sugars and lipid metabolism in humans. American Journal of Clinical Nutrition 62, Suppl., 250S-263S.

Girre C, Lucas D, Hispard E, Menez C, Dally S \& Menez JF (1994) Assessment of cytochrome P450 2E1 induction in alcoholic patients by chlorzoxazone pharmacokinetics. Biochemical Pharmacology 47, 1503-1508.

Horsmans Y, De Konninck X, Geubel A \& Pauwels S (1995a) Microsomal function in hepatitis B surface antigen healthy carriers: assessment of cytochrome P-450 1A2 activity by the 14C-caffeine breath test. Pharmacology Toxicology 77, 247249.

Horsmans Y, Geubel AP \& Pauwels S (1995b) Reliability of aminopyrine breath test using a single breath collection. Digestive Diseases and Sciences 40, 1581.

Keeffe EB, Adesman PW, Stenzel P \& Palmer RM (1987) Steatosis and cirrhosis in an obese diabetic. Resolution of fatty liver by fasting. Digestive Diseases and Sciences 32, 441-445.

Kharasch E, Hankins D, Mautz D \& Thummel KE (1996) Identification of the enzyme responsible for oxidative halothane metabolism: implications for prevention of halothane hepatitis. Lancet 347, 1367-1371.

Krishnaswamy K, Kalamegham R \& Naidu NA (1984) Dietary influences on the kinetics of antipyrine and aminopyrine in human subjects. British Journal of Clinical Pharmacology 17, 139-146.

Kuwahara M \& Hachimura K (1980) Image enhancement and left ventricular contour extraction techniques applied to radioisotope angiocardiograms. Automedica 3, 107-119.

Leclercq I, Desager JP \& Horsmans Y (1998a) Inhibition of chlorzoxazone metabolism, a clinical probe for CYP2E1, by a single-dose watercress ingestion. Clinical Pharmacology and Therapeutics 64, 144-149.

Leclercq I, Horsmans Y \& Desager JP (1998b) Estimation of chlorzoxazone hydrolase activity in liver microsomes and of the plasma pharmacokinetics of chlorzoxazone by the same highperformance liquid-chromatographic method. Journal of Chromatography 4, 291-296.

Lee RG (1989) Nonalcoholic steatohepatitis: a study of 49 patients. Human Pathology 20, 594-598.

Mortelmans L, Nuyts Y, Van Pamel G, Van Den Magdenbergh V, De Roo M \& Suetens P (1986) A new thresholding method for volume determination by SPECT. European Journal of Nuclear Medicine 12, 284-290.

Osawa H \& Mori Y (1996) Sonographic diagnosis of fatty liver using a histogram technique that compares liver and renal cortical echo amplitudes. Journal of Clinical Ultrasound 24, 25-29.

O'Shea D, Davis SN, Kim RB \& Wilkinson GR (1994) Effect of fasting and obesity in humans on the 6-hydroxylation of chlorzoxazone: A putative probe of CYP2E1 activity. Clinical Pharmacology and Therapeutics 56, 359-367.

Ploeg RJ, D'Alessandro A, Knechtle S, Stegall MD, Pirsch JD, Hoffmann RM, Sasaki T, Sollinger HW, Belzer FO \& Kalayoglu M (1993) Risk factors for primary dysfunction after liver transplantation - a multivariate analysis. Transplantation 55, 807-813.

Raucy JL, Lasker JM, Lieber C \& Black M (1989) Acetaminophen activation by human cytochromes P450IIE1 and P450IA2. Archives of Biochemistry and Biophysics 271, 270-283.

Sheiner LB (1983) ELSFIT (Version 3.0) A program for the extended least squares fit to individual pharmacokinetic data. San Francisco, CA: University of California.

Song BJ, Veech RL \& Saenger P (1990) Cytochrome P450IIE1 is elevated in lymphocytes from poorly controlled insulin-dependent diabetics. Journal of Clinical Endocrinology and Metabolism 71, 1036-1040.

Tapner M, Liddle C, Goodwin B, George J \& Farrell GC (1996) Interferon gamma down-regulates cytochrome P450 3A genes in primary cultures of well-differentiated rat hepatocytes. Hepatology 24, 367-373.

Weltman MD, Farrell GC, Hall P, Ingelman-Sundberg M \& Liddle C (1998) Hepatic cytochrome P450 2E1 is increased in patients with nonalcoholic steatohepatitis. Hepatology 27, 128-133.

Yun YP, Casazza JP, Sohn DH, Veech RL \& Song BJ (1991) Pretranslational activation of cytochrome P450IIE1 during ketosis induced by a high fat diet. Molecular Pharmacology 41, 474-479. 